\title{
Autotraducción, América Latina y la diáspora latina'
}

\author{
Rainier Grutman \\ rgrutman@uottawa.ca
}

https://orcid.org/0000-0002-5947-5751

School of Translation and Interpretation, University of Ottawa, Canadá

\author{
María Laura Spoturno² \\ lauraspoturno@gmail.com \\ https://orcid.org/0000-0002-9678-5767 \\ Universidad Nacional de La Plata; IdIHCS, UNLP, Consejo Nacional de \\ Investigaciones Científicas y Técnicas, Argentina
}

En el complejo escenario de las escrituras bilingües, la lengua es siempre un espacio de expresión pero también de conflicto y tensión. Este número especial se propone indagar sobre una forma particular de escritura bilingüe: la autotraducción. En cuanto instrumento a la vez estético y político, la autotraducción desempeña un rol fundamental en la (re)configuración de la identidad autoral en y a través de distintos espacios lingüísticos, literarios, culturales y políticos. Al explorar de manera específica el fenómeno de la autotraducción en las muy diversas regiones que se agrupan bajo el término general América Latina y en la llamada diáspora latina ${ }^{3}$, este número busca ampliar nuestro conocimiento sobre el tema y abrir nuevas líneas de investigación. Por cierto, autores consagrados como Guillermo Cabrera Infante, Ariel Dorfman, Rolando Hinojosa, Vicente Huidobro, Manuel Puig o las celebradas escritoras portorriqueñas Rosario Ferré y Esmeralda Santiago han recibido su cuota de atención crítica, pero el enfoque en la escritura latinoamericana en sí como sitio de autotraducción es mucho más reciente (Balderston y Schwartz, 2002; Antunes, 2009; del Río Zamudio, 2011; Antunes y Grutman, 2014).

$\mathrm{Al}$ iniciar la preparación del presente número, se publicó un volumen monográfico que revelaba, entre otros, la urgencia de estudiar la autotraducción como forma de escritura en diversos pueblos originarios de América Latina (Bujaldón de Esteves, Bistué y Stocco, 2019). La relación de las prácticas autotraductoras con el proceso de revitalización de las lenguas originarias puede considerarse uno de los grandes avances en materia de autotraducción de la última década, aunque las experiencias fundacionales de esas prácticas

1 Este número especial es fruto de una colaboración iniciada en 2019 y subsidiada por la Universidad de Ottawa, Canadá (FOAP: 603553-121099-2004/ RE 153890).

2 Investigación financiada por la Agencia Nacional de Promoción Científica y Tecnológica [PICT 2017-2942], el Consejo Nacional de Investigaciones Científicas y Técnica y la Universidad Nacional de La Plata [H/825 2017-2021], Argentina.

3 Somos conscientes del peso político que implica el uso de conceptos y términos como "América Latina", “diáspora” y "latina”. Al respecto, podrá consultarse, entre otros, MacDonald (2001), Fernández (2008), Torres Martínez (2016). 
se remontan a la década de los años ochenta del siglo pasado, en el caso del mapuzungun, e incluso antes, como lo muestra el caso del guaraní. El año 1992 aparece, sin embargo, como un hito en la concienciación sobre la situación de los pueblos originarios marginados por sucesivas y diversas formas de colonialismo. Dado el auge de este fenómeno en casi toda América Latina, la autotraducción desde o hacia las llamadas lenguas indígenas no podía estar ausente de este número especial. En los trabajos aquí incluidos, firmados respectivamente por Melisa Stocco, Javier Aguirre Ortiz y Paola Mancosu, se aborda el caso de autoras y autores que trabajan con el mapuzungun (Chile y Argentina), el guaraní (Paraguay) y el quechua (Perú) pero también con el wichí y el qom (Argentina y Bolivia). Todas estas lenguas se combinan con el español en la escritura. Queda, pues, pendiente estudiar la relación de las lenguas originarias de Brasil con el portugués desde la perspectiva que ofrece la autotraducción.

De todos modos, Brasil aparece representado en este número especial. Vinculado al fenómeno del exilio, el caso de Juana Manso, estudiado por Ana Eugenia Vázquez, revela las trayectorias lingüísticas y literarias de esta notable mujer argentina del siglo XIX, quien aprovechó su larga estancia en Brasil para enriquecer su obra de textos en portugués que luego se incorporaron a su obra en español. La experiencia del exilio en relación con situaciones de bilingüismo literario es problematizada también en otros artículos del número. Así, María Eugenia Ghirimoldi describe las intervenciones hechas por la autora argentina Laura Alcoba, exiliada en Francia a causa del golpe de Estado de 1976, en la traducción al español de su novela Manèges. Petite histoire argentine. Por su parte, la investigación de Trish Van Bolderen pone de relieve las prácticas autotraductoras principalmente en relación con la comunidad de inmigrantes de Chile que se exilió en Canadá tras el golpe de Estado de 1973.

Conviene no olvidar que los países de la región latinoamericana han sido marcados también por varias olas de inmigración provenientes no solo de las denominadas "antiguas patrias" española o portuguesa, sino también de toda Europa. Sobra mencionar la larga presencia italiana en Argentina, Uruguay,
Venezuela y Brasil, que sin duda ha dejado huellas en la trama cultural, así como en las literaturas de todos estos países. Los trabajos aquí recogidos hacen resaltar otro sector significativo de la migración en las Américas, que corresponde a la comunidad judía. Al igual que Nueva York y Montreal, Buenos Aires ha sido y sigue siendo una referencia en el mundo askenazít ${ }^{4}$ En este número, la sobrevivencia del ídish la representa el nombre de Ilan Stavans, nacido en México pero radicado en los Estados Unidos, que se ha convertido en una figura clave de las diásporas judía y latina. Maria Carmen África Vidal Claramonte analiza en su artículo la muy original trayectoria del autor entre las tres lenguas que singularizan su expresión: el español, el ídish y el inglés. Hay, sin embargo, otra vertiente importante de la cultura judía, mucho más vinculada a la historia y al destino del español. Son las comunidades sefardíes, cuya lengua patrimonial es abordada en este número por Cynthia Gabbay en sus múltiples aspectos relativos a la (auto)traducción.

Algunas de las contribuciones de este número de Mutatis Mutandis indagan también áreas de estudio más recientes en el campo de la autotraducción. Maria Alice Antunes aborda el caso de la autotraducción académica efectuada en Brasil por especialistas que traducen su producción del portugués al francés y al inglés para dar mayor visibilidad y difusión a su trabajo. Asimismo y como lo muestra el artículo de Sabrina Solange Ferrero, la influencia de las redes sociales y de los nuevos modos y medios de producción resulta un área de estudio inquietante para repensar la autotraducción en la actualidad (Desjardins, 2019).

\footnotetext{
4 Precisamente, la obra Un di velt hot geshvign, del Premio Nobel Elie Wiesel, que da origen a La Nuit, se publicó en ídish en Buenos Aires. El texto en ídish era mucho más extenso y llevaba un título más comprometido, cuya traducción al español sería "y el mundo se quedó en silencio" (Wiesel, 1956). Años más tarde, Wiesel ayudó a su esposa, Marion Erster Rose, a preparar una segunda traducción inglesa (una primera versión, firmada por Stella Rodway, había aparecido en 1960), siempre a partir de la autotraducción francesa que él había efectuado.
} 
En síntesis, este breve recorrido nos permite confirmar el interés de especialistas procedentes de distintos centros de investigación por el estudio de la autotraducción. En este número, la autotraducción se aborda en relación con problemáticas que afectan doce lenguas que se inscriben en escenarios de gran complejidad social, cultural y política. Seis de esas lenguas corresponden a las comunidades indígenas de la denominada América Latina mientras que las otras seis se identifican como lenguas europeas, que, en dos casos, llevan la marca de un evidente pasado imperial y colonial. Sin dudas, la región más estudiada en el número es América del Sur. No obstante, y como pone de relieve la colaboración de Rainier Grutman, es vital seguir indagando sobre las prácticas de autotraducción en América Central, región sobre la que existen algunos trabajos, así como sobre la experiencia de las comunidades latinas en Estados Unidos, que ha sido objeto de numerosas investigaciones, también en relación con la autotraducción (Gentes y Van Bolderen, 2018). Asimismo, y como señala Julio-César Santoyo en la entrevista, queda pendiente aún abordar el estudio de la autotraducción y de su historia fuera del llamado Occidente. Sin duda, esa mirada aportará al desarrollo del campo. A continuación, presentamos de manera separada las muy valiosas contribuciones que integran el volumen Autotraducción, América Latina y la diáspora latina.

En "Más allá del paradigma monolingüe: la autotraducción literaria en lenguas indígenas en Argentina", Melisa Stocco presenta un panorama sobre la autotraducción literaria en el campo de las literaturas de autoría indígena en el territorio que hoy conocemos como Argentina. Con la atención puesta en la producción artística de Liliana Ancalao (mapuche), Mario Castells (guaraní), Lecko Zamora (wichí) y Víctor Zárate (qom), la autora muestra la vigencia del imaginario monolingüe castellano que domina el sistema literario y las políticas editoriales en Argentina y relega las literaturas que aquí ocupan su atención al lugar de lo "marginal" y "exótico". En el desarrollo de su trabajo, Stocco examina el potencial de la autotraducción como práctica no solo interlingüística e intercultural sino también, y especialmente, como instrumento eficaz para cuestionar y problematizar los regímenes de legitimación de la palabra así como la determinación de un canon literario monolingüe desde un punto de vista político, ético y estético.

En el artículo "La pregunta por el original en las ediciones bilingües de poesía mapuche", Javier Aguirre Ortiz se interesa por el rol que desempeña el mapuzugun en las ediciones bilingües de poesía mapuche, en las que la aparente paridad textual no se corresponde con una paridad sociolingüística. Las ediciones bilingües, aunque promuevan efectivamente la visibilización del mapuzugun (más aún cuando se atribuyen ambas versiones a la misma persona autotraductora), siguen restando autonomía a una lengua en retroceso y favoreciendo al español dominante. El corpus que se examina en este artículo parte de la consideración de la producción de Sebastián Queupul y sigue con la obra de otras autoras y otros autores clave como Lorenzo Aillapan, Elicura Chihuailaf, Pedro Aguilera Milla, Leonel Lienlaf, María Isabel Lara Millapán y Bastián Chandía Millanaw.

En su artículo "La autotraducción en la poesía quechuadeCh'aska Anka Ninawaman", PaolaMancosu examina la poesía bilingüe quechua-español de Eugenia Carlos Ríos publicada bajo el seudónimo "Ch'aska Anka Ninawaman". Como Aguirre Ortiz, Mancosu considera las dimensiones de poder y, en particular, de diglosia que afectan la autotraducción decolonial. Además de examinar la asimetría entre las lenguas (y culturas) involucradas, el artículo hace hincapié en el posicionamiento ideológico de la autotraductora. Este último se evidencia en los paratextos que acompañan los poemas mientras que los propios poemas exhiben estrategias como la reescritura y el heterolingüismo.

En "Neodjudezmo en la lírica latinoamericana disidente: la construcción de registros intersticiales entre la autotraducción y el glosario", Cynthia Gabbay estudia la nueva poesía judeoespañola (djudezma) en Argentina (Denise León) y en México (Myriam Moscona). En ambos casos, aparece el famoso poemario Dibaxu, de Juan Gelman (1994), como hipotexto y como evento epistémico, es decir, como productor intertextual de un nuevo saber. Con relación a los mecanismos metalingüísticos identificados a 
la hora de publicar poesía en neodjudezmo y en comparación con la propuesta de lectura intersticial de Gelman, el artículo examina las manifestaciones translingüísticas de los textos y verifica sus efectos sobre la divergencia de género que plantea. Por último, la autora postula que, al resistirse a la modernidad, en su disidencia, la poesía en neodjudezmo produce una vanguardia poética.

Por su parte, en "Factores que condicionan la autotraducción. El caso de Los Misterios del Plata, de Juana Manso", Ana Eugenia Vázquez repara en una serie de aspectos sociales y glotopolíticos que afectan la preparación de la versión española de $O s$ Mysterios del Plata, novela escrita por Juana Manso en 1852 durante su exilio en Brasil. Vázquez pone en valor las condiciones de producción del texto brasileño de partida y de su reconfiguración argentina que comprometen la figura de esta muy relevante autora, feminista y pionera de la educación argentina. El estudio descubre así el papel clave que tienen estas operaciones lingüístico-culturales en la gestión estratégica de Manso como autora y representante de la llamada "novela nacional".

En "Traducción revisada por la autora: la semiautotraducción en La casa de los conejos de Laura Alcoba", María Eugenia Ghirimoldi aborda la producción narrativa de una escritora argentina que, por ser hija de militantes, debe exiliarse en Francia junto a su familia durante la última dictadura en Argentina. Ghirimoldi examina las tensiones de la escritura de Alcoba a partir del estudio de su novela Manèges. Petite histoire argentine y de sus dos traducciones al español. La segunda traducción, efectuada con la colaboración de la propia Alcoba, resulta de particular interés para ponderar aspectos relativos al posicionamiento autoral en el terreno de la semiautotraducción. El análisis invita a la reflexión más amplia sobre la lengua, entendida como sitio de conflicto y deseo, en la obra de Alcoba.

En "The Spanish imposition: Literary self-translation into and out of Spanish in Canada (19712016)", Trish Van Bolderen explora el caso de la autotraducción literaria en un corpus de obras producidas por veinticinco autoras y autores que se autotradujeron del español o al español entre 1971 y 2016 en Canadá. En su mayoría, se trata de personas que inmigraron desde Chile después del golpe de Estado de Pinochet. También hay tres autores de origen anglosajón (Estados Unidos, Escocia, Gales) que utilizan el español en su trabajo, además de dos personas nacidas en Canadá. Van Bolderen examina con detalle este corpus a partir de varios parámetros: el espacio, el tiempo, la variedad lingüística y las lenguas combinadas con el español (el inglés, el francés o ambos idiomas). La investigación de Van Bolderen contribuye así a la descripción del paisaje lingüístico, literario y cultural de Canadá.

En su artículo, "La autotraducción y el original secundario en Ilan Stavans: ser traduciendo, traducirse para ser", $\mathrm{M}^{\mathrm{a}}$ Carmen África Vidal Claramonte parte de la consideración inicial de la autotraducción como fenómeno político que se materializa mediante múltiples procedimientos en espacios atravesados y constituidos por la hibridez, la transformación y el movimiento constantes. Las reflexiones de Vidal Claramonte se centran en la profusa obra del escritor, traductor e investigador Stavans. Su producción, publicada principalmente en Estados Unidos, da cuenta de una identidad que se dirime en una zona indecisa habitada, entre otras lenguas, por el inglés, el español y el ídish. El estudio, que se propone examinar la teoría borgiana de Stavans sobre la traducción y la autotraducción, demuestra el potencial de la (auto) traducción no solo como garantía de la supervivencia de la obra del autor sino también como condición sine qua non de su propio ser.

En "Autotradução acadêmica: o caso da produção publicada no periódico acadêmico periférico plurilíngüe Ecos de Linguagem", Maria Alice Antunes examina el papel innegable de la (auto)traducción en el proceso de aumentar, mediante publicaciones bilingües, la visibilidad internacional de la investigación hecha en Brasil. Antunes aborda el fenómeno de la autotraducción académica; es decir, la traducción de un texto de especialidad realizada por el propio autor o la propia autora, a partir del caso de Ecos de Linguagem, una revista multilingüe que fomenta la lectura en varios idiomas sin renunciar a la publicación en portugués. Entre 2012 y 2018 se publicaron cincuenta y siete artículos, la mitad de los cuales fueron traducidos por sus autoras o autores. El estudio de Antunes, que se basa tam- 
bién en la realización de entrevistas con especialistas, complementa la tipología concebida por Verena Jung (2002).

El artículo de Sabrina Solange Ferrero, "La autotraducción como proceso legitimador de un ethos autoral en la obra de la artista Carla Quevedo", aborda y problematiza cuestiones caras a la autoría y la subjetividad en diversas prácticas textuales que, en sentido amplio, se inscriben en el ámbito de la autotraducción. Ferrero explora las particularidades que caracterizan la producción de la actriz e Instapoeta argentina Carla Quevedo, artista que trabaja en español e inglés y autotraduce su obra poética, y repara tanto en sus poemas publicados en la red social Instagram ${ }^{\circledR}$ como en el pasaje de esos textos a publicaciones más convencionales en papel. De este modo, la investigación de Ferrero contribuye a ampliar nuestras reflexiones para considerar la multimodalidad y la intermedialidad en pos de una redefinición de la categoría de autotraducción.

En su colaboración especial, "Autotraducción y asimetría en el mundo de habla hispana", Rainier Grutman plantea una serie de cuestiones generales a partir de una lectura pormenorizada de La autotraducción literaria en contextos de habla hispana (Europa y América) (Bujaldón de Esteves et al., 2019). Coordinado por tres investigadoras argentinas, este volumen colectivo aborda el fenómeno de la autotraducción en un territorio vasto que comprende la Península Ibérica y seis países de la región latinoamericana (Argentina, Chile, Guatemala, México, Paraguay y Perú). Esta perspectiva "transatlántica" permite identificar, a pesar (y más allá) de las diferencias entre cada contexto particular, ciertas regularidades que pueden contribuir a definir rasgos distintivos de la autotraducción en el mundo contemporáneo. Grutman destaca que la obra pone de relieve también una situación a la vez lógica y paradójica: mientras que la asimetría observada en la práctica autotraductora favorece la lengua española, las políticas de publicación científica tienden a marginalizarla, imponiéndole el inglés como lingua (supuestamente) franca.

Cierra este número especial, una entrevista realizada a Julio-César Santoyo, profesor emérito de la Universidad de León, pionero y autoridad indiscutible en los estudios sobre la autotraducción en general y, en particular, sobre su historiografía en Occidente. Consultado sobre su vasta experiencia y trayectoria como investigador en esta área de estudio, el profesor Santoyo revisa críticamente los hitos principales, los caminos recorridos y las áreas que, a su criterio, conviene explorar. Conforme avanza la entrevista, traza el terreno de la autotraducción y lo reilumina a partir de sus observaciones agudas. Como corolario, se ofrece, al final de la entrevista, una bibliografía completa de los trabajos publicados por el profesor Santoyo sobre este tema de investigación.

En su conjunto, las doce contribuciones que integran este número especial en torno a la autotraducción, América Latina y la diáspora latina constituyen un avance para nuestra disciplina. En el futuro, será productivo seguir avanzando en las líneas de investigaciones abordadas en este número $\mathrm{y}$, asimismo, poner en relación esas líneas con otras áreas de interés que también merecen nuestra atención. Así, será relevante valorar, entre otros aspectos, la incidencia de la autotraducción en el marco de activismos sociales y redes de lucha por los derechos humanos (Spoturno, 2022) así como problematizar la práctica autotraductora desde las perspectivas que aportan los enfoques traductológicos feministas y queer y en su vínculo con las literaturas destinadas a las infancias y a públicos juveniles, tema poco transitado en el ámbito latinoamericano. En un plano metodológico, se advierte la necesidad de precisar las nociones de agencia, autoridad y autoría implicadas en la autotraducción (Grutman y Van Bolderen, 2014; Grutman, 2018, 2021; Spoturno, 2019) y los roles que desempeñan diferentes agentes en el proceso de autotraducción (Santoyo, 2012; Dasilva, 2016; Manterola Agirrezabalaga, 2017).

Finalizamos esta presentación expresando nuestro más sincero agradecimiento al equipo editorial de Mutatis Mutandis, una revista que desde 2008 contribuye a visibilizar las investigaciones en traductología desde América Latina. Un reconocimiento especial va a su editora general, Paula Andrea Montoya Arango, por su inestimable trabajo de coordinación y revisión. Asimismo, agradecemos al grupo de especialistas que asumieron la tarea de evaluar los artículos, porque sus rigurosos dictámenes han contribuido, sin dudas, a la calidad de este número especial. 


\section{Referencias}

Antunes, M. A. (2009). O respeito pelo original - João Ubaldo Ribeiro e a autotradução. Annablume.

Antunes, M. A. y Grutman, R. (Eds.). (2014). Autotradução/Self-Translation. Tradução em Revista, 16 (número especial). https://www.maxwell. vrac.puc-rio.br/rev_trad.php?strSecao=fasciculo\&fas $=27149 \&$ numfas $=16$

Balderston, D. y Schwartz, M. E. (Eds.). (2002). Voice-Overs. Translation and Latin American literature. State University of New York Press.

Bujaldón de Esteves, L., Bistué, B. y Stocco, M. (Eds.) (2019). Literary self-translation in Hispanophone contexts - La autotraducción literaria en contextos de habla hispana. Europe and the Americas - Europa y América. Palgrave Macmillan.

Dasilva, Xosé Manuel. (2016). En torno al concepto de semiautotraducción. Quaderns, 23, 15-35. https://doi.org/2014-9735

Desjardins, Renée. (2019). A preliminary theoretical investigation into [online] social self-translation: the real, the illusory, and the hyperreal. Translation Studies, 12(2), 156-176. https://doi. org/10.1080/14781700.2019.1691048

Fernández, M. Mireya. (2008). Diáspora: la complejidad de un término. Revista Venezolana de Análisis de Coyuntura, XIV(2), 305-326. https:// www.redalyc.org/articulo.oa?

Gentes, E. y Van Bolderen, T. (2018). Self-Translation. Oxford Bibliographies. En I. Stavans (Ed.), Latino Studies. https://doi.org/10.1093/ OBO/9780199913701-0104

Grutman, R. y Van Bolderen, T. (2014). Self-Translation. En S. Berman y C. Porter (Eds.), A companion to translation studies (pp.323-332). Wiley Blackwell. https://doi. org/10.1002/9781118613504.ch24

Grutman, R. (2018). Autotraducción, autoría y autopromoción en el Siglo de Oro. Quaderns: revista de traducció, 25, 143-163. https://raco. cat/index.php/QuadernsTraduccio/article/ view/337845
Grutman, R. (2021). Infra-autotraduções versus supra-autotraduções: a dupla dinâmica da autotradução. (trad. L. F. Dias Pita) Tradução em Revista, 31(2), 249-280. https://doi. org/10.17771/PUCRio.TradRev.54939

Jung, V. (2002). English-German Self-translation of Academic Texts and its Relevance for Translation Theory and Practice. Peter Lang.

Manterola Agirrezabalaga, E. (2017). Collaborative self-translation in a minority language: Power implications in the process, the actors and the literary systems involved. En O. Castro, S. Mainer, S. Page (Eds), Self-Translation and power negotiating identities in European multilingual contexts (pp. 191-216). Palgrave Macmillan. https://doi. org/10.1057/978-1-137-50781-5_9

MacDonald, V.-M. (2001). Historiographic essay: Hispanic, Latino, Chicano, or "Other"? Deconstructing the relationship between historians and Hispanic-American educational history. History of Education Quarterly, 41(3), 365-413. https:// doi.org/10.1111/j.1748-5959.2001.tb00093.x.

Santoyo, J.-C. (2012). Autotraducciones: ensayo de tipología. En P. Martino Alba, J. A. Albaladejo Martínez y M. Pulido (Eds.), Al humanista, traductor y maestro Miguel Ángel Vega Cernuda (pp. 205-222). Dykinson.

Spoturno, M. L. (2019). El retrabajo del ethos en el discurso autotraducido. El caso de Rosario Ferré. Hermeneus. Revista de traducción e interpretación, 22, 323-354. https://doi.org/10.24197/ her.21.2019.323-354

Spoturno, M. L. (2022). Ethos colectivo, redes de lucha y prácticas de escritura y (auto)traducción en colaboración: El caso de Revenge of the Apple/ Venganza de la manzana, de Alicia Partnoy. Letral, 28, 46-72. https://doi.org/10.30827/rl. vi28.21366.

Torres Martínez, R. (2016). Sobre el concepto de América Latina ¿Invención francesa? $\mathrm{Ca}$ hiers d'Études Romanes, 32, 89-98. https://doi. org/10.4000/etudesromanes.5141

Wiesel, E. (1956). Un di velt hot geshvign. Unión Central Israelita Polaca.

Cómo citar este artículo: Grutman, R. y Spoturno, M. L. (2022). Autotraducción, América Latina y la diáspora latina. Mutatis Mutandis, Revista Latinoamericana de Traducción, 15(1), 2-7. https://doi. org/10.17533/udea.mut.v15n1a01 